University of Nebraska - Lincoln

DigitalCommons@University of Nebraska - Lincoln

Biological Systems Engineering: Papers and

Publications

Biological Systems Engineering

$1-15-2019$

\title{
Spatial Heterogeneity of Temporal Shifts in Extreme Precipitation across India
}

\author{
Manas Khan \\ University of Nebraska - Lincoln \\ Francisco Munoz-Arriola \\ University of Nebraska-Lincoln, fmunoz@unl.edu \\ Rehana Shaik \\ Indian Institute if Information Technologies \\ Penny Greer \\ University of Nebraska-Lincoln
}

Follow this and additional works at: https://digitalcommons.unl.edu/biosysengfacpub

Part of the Climate Commons, Fresh Water Studies Commons, and the Water Resource Management Commons

Khan, Manas; Munoz-Arriola, Francisco; Shaik, Rehana; and Greer, Penny, "Spatial Heterogeneity of Temporal Shifts in Extreme Precipitation across India" (2019). Biological Systems Engineering: Papers and Publications. 682.

https://digitalcommons.unl.edu/biosysengfacpub/682

This Article is brought to you for free and open access by the Biological Systems Engineering at DigitalCommons@University of Nebraska - Lincoln. It has been accepted for inclusion in Biological Systems Engineering: Papers and Publications by an authorized administrator of DigitalCommons@University of Nebraska Lincoln. 


\title{
Spatial Heterogeneity of Temporal Shifts in Extreme Precipitation across India
}

\author{
Manas Khan, ${ }^{1}$ Francisco Munoz-Arriola, ${ }^{1,2}$ \\ Shaik Rehana, ${ }^{3}$ and Penny Greer ${ }^{2}$ \\ 1 Department of Biological Systems Engineering, University of Nebraska-Lincoln, USA \\ 2 School of Natural Resources, University of Nebraska-Lincoln, USA \\ 3 International Institute of Information Technology, Hyderabad, India \\ Corresponding author - Francisco Munoz-Arriola, fmunoz@unl.edu
}

\begin{abstract}
When analyzing trends and patterns of extreme precipitation, one can easily generalize the shifts caused by external climate forcings and map a single temporal shift of annual precipitation. However, the complexity of a changing environment evidences spatially distributed shifts particularly those of extreme precipitation which are essential in planning and designing enterprises and, ultimately, in managing infrastructure across scales. The goal of this study is to characterize the spatial heterogeneity of shifts in the increasing pace of extreme events over India. The study has a two-part hypothesis: (1) the number of grid cells with significant trends in annual precipitation (P), extreme precipitation (R95) and very extreme precipitation (R99) will reflect the extent of geophysically vulnerable areas subject to increasing or decreasing annual precipitation and (2) the dispersion of cells with significant shifting points (which has occurred at different historical periods) will evidence the heterogeneity of the changes in P, R95 and R99 regimes.

To test this hypothesis, we used the Mann-Kendall and Pettitt's tests to estimate the significance of the increasing and decreasing trends and shifting points, respectively, in P, R95 and R99 from 1901-2015 for mainland India.
\end{abstract}

Published in Journal of Climate Change, Vol. 5, No. 1 (2019), pp. 19-31. doi:10.3233/JCC190003

Submitted August 20, 2018; revised and accepted November 15, 2018 
Based on a gridded dataset of $0.25^{\circ}$ resolution, results showed significant temporal trends for spatially averaged R95 and R99, whereas non-significant inclining temporal trend was found for P. Trend analyses applied to the precipitation gridded product of the Indian Meteorological Department revealed statistically significant trends for almost 38\%, 36\% and 31\% of India's territory for P, R95 and R99, respectively. Further, the magnitude of these trends proved higher for R95 (i.e., $0.42 \mathrm{~mm}$ year-1) compared with R99 (i.e., o.31 $\mathrm{mm}$ year-1), supporting the idea of an increasing liability for flash floods. Results also showed that most of the temporal shifts in the time series of P, R95 and R99 occurred between 1941-1980, at 34\%, 31\% and 22\% of the grids, respectively. In addition, the opposite trends before and after the inflection point were found for locations showing significant temporal shifts in R95 and R99.

Keywords: Change point, Mann-Kendall, Pettitt's test, Extreme precipitation

\section{Introduction}

Under a changing climate, the frequency and magnitude of extreme precipitation events are expected to increase along with the intensification of the hydrological cycle (Allen and Ingram, 2002; Rajeevan et al., 2008; Wu et al., 2013), leading to an increase in extreme dry and wet spells (Stocker et al., 2013). While extreme precipitation events have been increasing throughout the globe (Alexander et al., 2006; Min et al., 2011; Westra et al., 2013), the corresponding increase in the amount of total precipitation is non-significant (Trenberth, 2011). The World Meteorological Organization estimated that the global losses due to extreme weather events is about US\$50-100 billion annually while the loss of life is about 2,500,000 (De et al., 2005). In countries like India, where the economy depends on agriculture, the variability in extreme precipitation events can affect the sustainability of food production and the inherent urban and rural livelihoods (De et al., 2005). As further examples, extreme precipitation and floods in Uttarakhand in 2013 affected around 5000 people and the 2015 floods in the city of Chennai damaged approximately 57,00o houses according to the final report of the Disaster Relief Emergency Fund (2016). Thus, studying shifts in the intensity of precipitation is critical to the sustainability and resilience of infrastructure (agriculture, water, energy and ecosystem services, among others).

Numerous studies have adopted various indices to analyze and characterize the intensity and frequency of Indian precipitation extremes 
(Goswami et al., 2006; Rajeevan et al., 2008; Vittal et al., 2013; Ali et al., 2014; Kotal et al., 2014; Vinnarasi and Dhanya, 2016; Meher et al., 2018) and their duration (Dash et al., 2009). Those assessments were based on fixed thresholds (Sushama et al., 2014; Vinnarasi and Dhanya, 2016) as well as statistics of extreme precipitation (Ghosh et al., 2012; Vittal et al., 2013). In areas dominated by monsoonal precipitation, the complexity of precipitation patterns and trends can be evidenced by the increase in extreme precipitation between 1951 and $2000\left(>120 \mathrm{~mm} \mathrm{day}^{-1}\right)$ and the lack of significance in the average monsoonal precipitation's trend (Goswami et al., 2006, and Rajeevan et al., 2008). However, other studies found no evidence of such increase (Krishnamurthy et al., 2009; Ghosh et al., 2009) or found that the non-uniform trends of extreme rainfall were associated with an increase in precipitation's variability (Ghosh et al., 2012), which opposed what Singh and Ranade (2009) found previously when they assessed the changes in rainfall intensity during wet and dry events.

Some of these shifts in magnitude and frequency of extreme monsoon precipitation over India have been identified as taking place in 1950 and 1975 (Vittal et al., 2013). The lack of a consistent reference of changes in extreme precipitation trends, and the associated spatial distribution inflection points, also indicate the complexity of the spatiotemporal patterns in extreme precipitation. The present study lays out a plan to identify how annual extreme precipitation and its associated temporal shifts occur at finer resolutions $(0.25 \times 0.25)$ so that eventual large-scale reassessments on infrastructure evaluation, (re)design and planning can be implemented across different areas in India. In this study, it is hypothesized that (1) the number of grid cells with significant trends in P, R95, and R99 will reflect the extent of geophysically vulnerable areas subject to increasing or decreasing annual precipitation and (2) the dispersion of cells with significant shifting points (which has occurred at different historical periods) will evidence the heterogeneity of the changes in annual precipitation, extreme precipitation and very extreme precipitation regimes. The spatiotemporal variations in the extreme precipitation indices are analyzed at a $0.25^{\circ} \times 0.25^{\circ}$ resolution using a gridded data base for a period of 115 years (1901 to 2015).

The present study also aims to characterize the areas at which shifts and the increasing pace of extreme events could affect the current 
infrastructure and its adaptive capability. Thus, to test the two-part hypothesis above and achieve the proposed goal, we will address the following re search objectives:

1. Determine the spatial distribution of extreme precipitation trends using the Mann-Kendall test.

2. Identify the temporal shifts of extreme precipitation applying Pettitt's test.

This paper is organized as follows: The second section describes the materials and methodology; the third section describes the results and discussion; and the last section is the conclusion.

\section{Materials and Methods}

\section{Study Area and Input Data}

The present study focused on the Indian subcontinent, which was divided into seven meteorologically homogeneous regions (Figure 1). Gridded daily precipitation data at a $0.25^{\circ} \times 0.25^{\circ}$ resolution was collected from the India Meteorological Department (IMD) (Pai et al., 2014) for the period 1901-2015, covering 4964 grids. The new fine-resolution data sets were also tested by Pai et al. (2014) for the comparability of large-scale climatological features of rainfall all over India with the existing IMD rainfall data sets at $0.5^{\circ} \times 0.5^{\circ}$ and $1^{\circ} \times 1^{\circ}$ resolutions (Rajeevan et al., 2008). The daily rainfall records were generated from 6955 rain gauge stations with varying availability whereas the density of the stations was relatively high in the south Peninsula. Over the northern, northwest, northeast and eastern parts of central India, the density of stations was relatively low (Pai et al., 2014). Normal annual precipitation was approximately $1139 \mathrm{~mm}$ with a maximum value of about $5390 \mathrm{~mm}$ for the period 1901-2015 whereas the mean and maximum values of the standard deviation of annual precipitation were approximately $341 \mathrm{~mm}$ and $4080 \mathrm{~mm}$, respectively (Figure 1). 


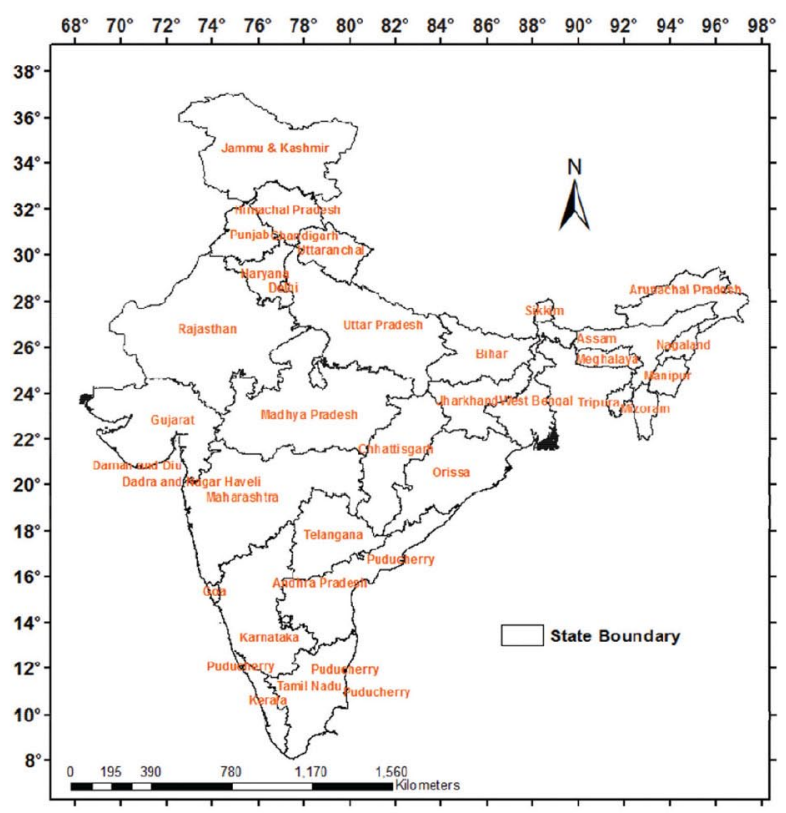

(a)

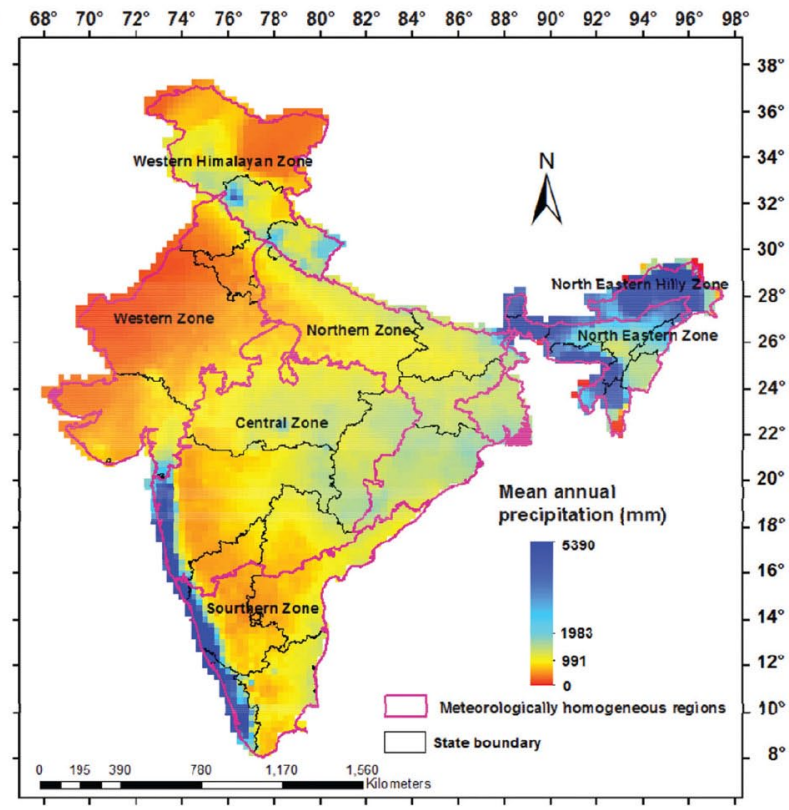

(b)

Figure 1: (a) State boundary of India, (b) Mean annual precipitation from 19012015 over India.

\section{Methodology}

\section{Calculation of Extreme Indices}

This study used two extreme precipitation indices, extreme precipitation (R95) and very extreme precipitation (R99), as proposed by the Expert Team on Climate Change Detection and Indices, a joint venture of the World Meteorological Organization (WMO), the Commission for Climatology, the World Climate Research Programme and the Joint Commission for Ocean Monitoring (https://www.wcrp-climate.org/ etccdi). R95 and R99 were defined as the annual accumulated amount of precipitation above the 95th and 99th percentiles based on the period 1960-1990, suggested by the WMO. We used RCLIMDEX software packages (additional information may be obtained at http://acmad. net/rcc/procedure/RClimDexUserManual.pdf) to calculate the extreme precipitation indices at each grid of the IMD data $\left(0.25^{\circ} \times 0.25^{\circ}\right)$. 


\section{Trend Analysis}

The Mann-Kendall test (Mann, 1945; Kendall, 1955) was used to analyze trends for P, R95 and R99 between 1901 and 2015 for each of the IMD grid points at the 95\% significance level. The Mann-Kendall test is a non-parametric trend assessment with the null (Ho) and alternate $(\mathrm{Ha})$ hypothesis stated as follows:

Ho: No monotonic trend; Ha: Monotonic trend is present

- At first, the data were arranged in the order they were collected over time, $X_{1}, X_{2} \ldots X_{\mathrm{n}}$, which variables denote the measurements obtained at times $1,2 \ldots n$, respectively.

- Then, all $n(n-1) / 2$ possible differences $x_{i}-x_{i}$ or signs (where $i>j$ ) were determined which will produce the following combinations:

$$
\begin{aligned}
& x_{2}-x_{1}, x_{3}-x_{1} \ldots \ldots \\
& \operatorname{sign}\left(x_{i}-x_{j}\right)= \begin{cases}1 & \text { if } \boldsymbol{x}_{i}>x_{j}, x_{3}-x_{2}, x_{4}-x_{2} \ldots x_{n}-x_{n-1} \\
0 & \text { if } \boldsymbol{x}_{i}=\boldsymbol{x}_{j} \\
-1 & \text { if } \boldsymbol{x}<\boldsymbol{x}_{i j}\end{cases}
\end{aligned}
$$

- Then the $S$ statistic was calculated in the following manner:

$$
S=\sum_{i=2}^{n} \sum_{j=1}^{i-1} \operatorname{sign}\left(x_{i}-x_{j}\right)
$$

- When $S$ was a positive number, later observations tended to be larger than earlier observations.

- After that, the variance of $S$ was calculated using the following formulae:

$$
\operatorname{VAR}(S)=\frac{1}{18}\left[n(n-1)(2 n+5)-\sum_{p=1}^{g} t_{p}\left(t_{p}-1\right)\left(2 t_{p}+5\right)\right]
$$

where $g$ is the number of tied groups and $t_{p}$ is the number of observations in the $p^{\text {th }}$ group. 
- Now the Mann-Kendall $Z$ statistic was calculated as follows:

$$
\begin{aligned}
& Z_{M K}=\frac{s-1}{[\operatorname{VAR}(S)]^{1 / 2}} \text { when } S>0 \\
& Z_{M K}=0 \quad \text { when } S=0 \\
& Z_{M K}=\frac{S+1}{[\operatorname{VAR}(S)]^{1 / 2}} \text { when } S<0
\end{aligned}
$$

- A positive (negative) value of $Z_{M K}$ indicates that the data tend to increase (decrease) with time.

- $H_{o}$ is rejected if $\left|Z_{M K}\right|>\left|Z_{(1-\alpha / 2)}\right|$ where the $Z$ value is calculated from a normal distribution. $\alpha$ denotes a Type I error.

After detecting the trend in the time series, we calculated the magnitude of trend $\left(Q_{\text {sen }}\right)$ through non-parametric methods proposed by Sen (1968) and Hirsch et al. (1982), which are as follows:

$$
Q_{i}=\left[\frac{y_{i}-y_{j}}{x_{i}-x_{j}}\right] \quad i=1,2, \ldots \ldots n \quad \text { where } j<i
$$

where $Y_{i}$ and $Y_{j}$ are data points at $X_{i}$ and $X_{j}$, respectively. All the $n$ number of values of $Q_{i}$ are arranged from the smallest to largest order, and the median of this series is determined as the value of Sen's slope $(Q)$, which is as follows:

$$
\begin{array}{rlrl}
Q & =Q_{(n+1) / 2} & & \text { if } n \text { is odd } \\
& =1 / 2\left(Q_{n / 2}+Q_{(n+2) / 2}\right) & \text { if } n \text { is even }
\end{array}
$$

A positive (negative) value of $Q$ will infer an increasing (decreasing) trend of the time series.

\section{Change Detection Analysis}

To detect change points in the time series, we applied Pettitt's test (Pettitt, 1979). According to this method, a change point is found by comparing whether the distribution function, $F_{1}(x)$, of the variables from $X_{1}$ to $X_{t}$ is different from the distribution function, $F_{2}(x)$, of the random variables from $X_{t+1}$ to $X_{T}$. The test statistic $K_{Y}$ was calculated as follows: 


$$
K_{T}=\max _{1 \leq t<T}\left|S_{i}\right|
$$

where test statistic $S_{i}$ was determined as

$$
S_{i}=\sum_{i=1}^{t} \sum_{j=1}^{T} R_{i j}
$$

where

$$
R_{i j}=\operatorname{sign}\left(X_{i}-X_{j}\right)=\left\{\begin{array}{cc}
-1 & \text { when }\left(X_{i}-X_{j}\right)<0 \\
0 & \text { when }\left(X_{i}-X_{j}\right)=0 \\
1 & \text { when }\left(X_{i}-X_{j}\right)>0
\end{array}\right.
$$

A $p$-value was then calculated by the following formulae:

$$
p=2 \cdot \exp \left(\frac{-6 K_{T}^{2}}{T^{2}+T^{3}}\right)
$$

If the calculated $p$-value is less than a defined significance level $(\alpha)$, a change point is found.

\section{Results}

\section{Trend Analysis}

\section{Trend Analysis of Annual Mean Precipitation (P)}

A trend analysis was performed for a time series of the spatially averaged annual mean and standard deviation (SD) of $P$ for the period 1901-2015. A non-significant increasing trend was found for both the annual averaged mean and SD of $P$ (Figure 2a). From the trend analysis at the grid scale, it was found that approximately $18.11 \%, 20.29 \%$ and $61.6 \%$ of grid cells were showing a significant increasing trend, a significant decreasing trend and a non-significant trend, respectively, for annual precipitation from 1901-2015 (Figure 3a). A significant decreasing trend of annual mean $P$ was found mostly in Chhattisgarh, Madhya Pradesh, Uttar Pradesh, Arunachal Pradesh, Assam, Nagaland, Uttaranchal and Kerala (Figure 4a). On the other hand, a significant increasing trend was found mostly in the Western Ghats, Andhra Pradesh, Meghalaya, West Bengal and Jammu and Kashmir. The magnitude of the trend of mean precipitation found varied from $-21.5 \mathrm{~mm}$ year ${ }^{-1}$ to $46.9 \mathrm{~mm}$ year ${ }^{-1}$. 

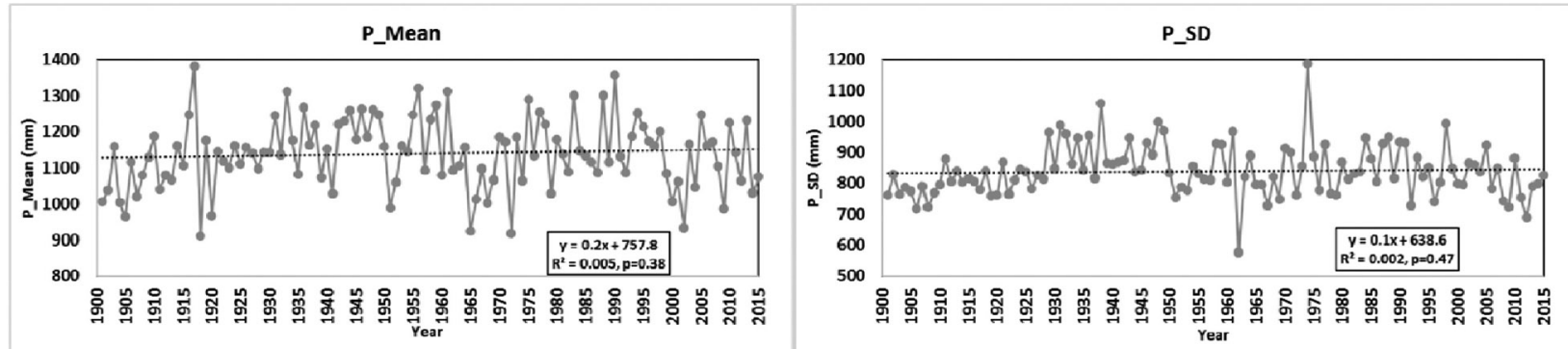

(a)
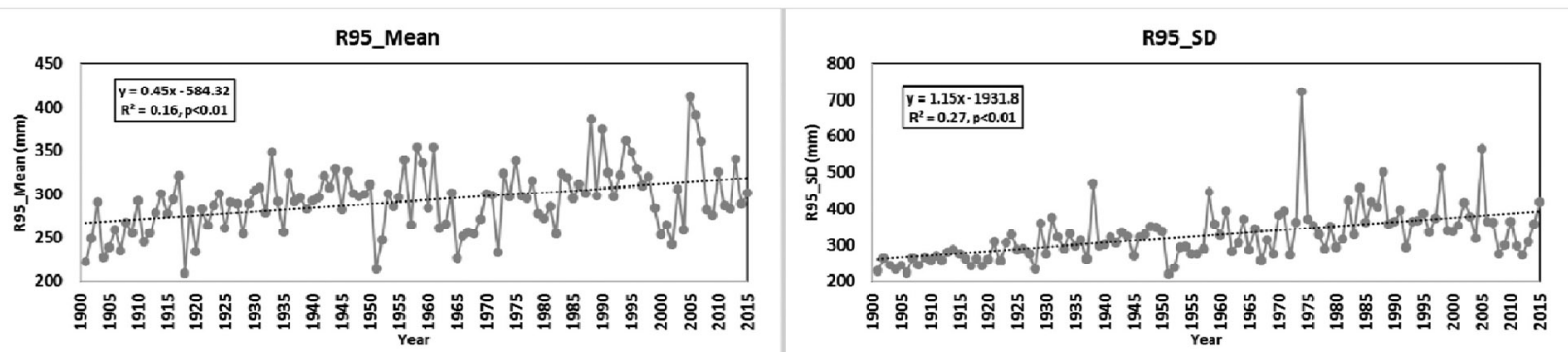

(b)
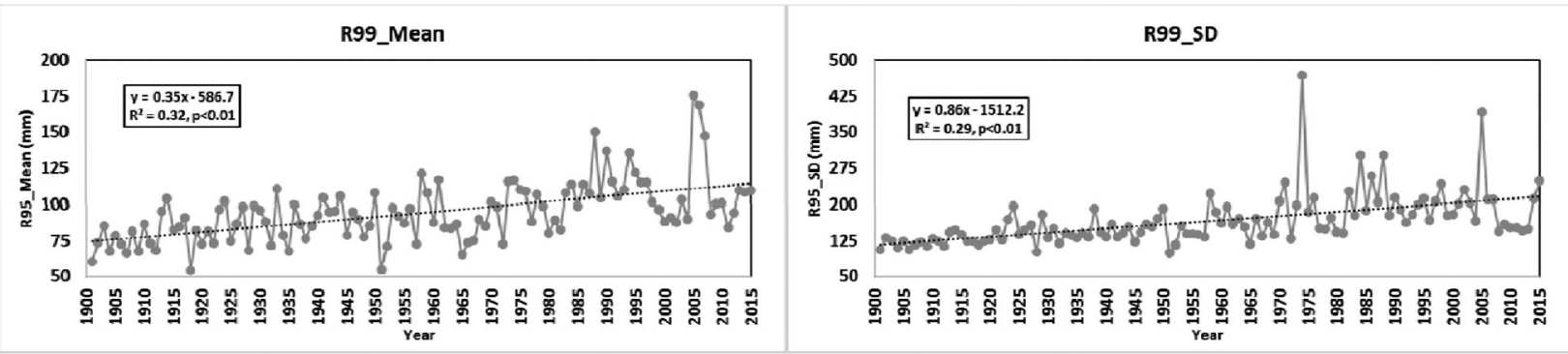

(c)

Figure 2: Temporal variation of annual mean and standard deviation (SD) of (a) annual precipitation (P), (b) heavy precipitation (R95), and (c) extreme precipitation (R99) for the period 1901-2015 for all of India.

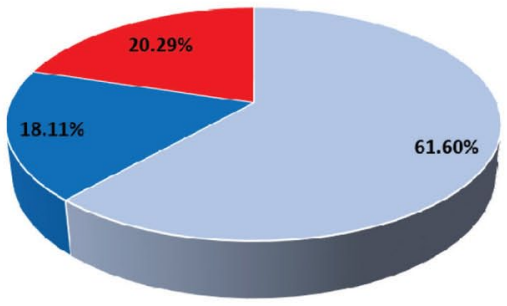

(a)

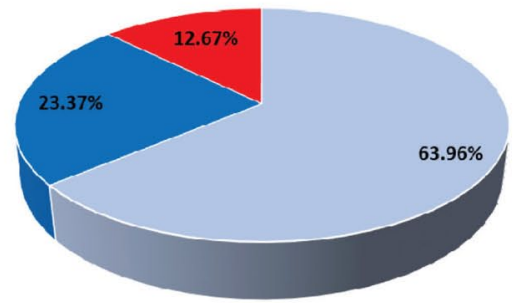

NS S_I S_D

(b)

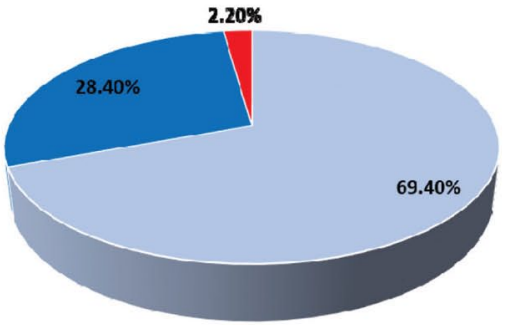

(c)

Figure 3: Percentage of grid cells showing non-significant (NS), significantly increasing (S_I) and significantly decreasing (S_D) trend for (a) P, (b) R95, and (c) R99 at 95\% significance level from 1901-2015. 


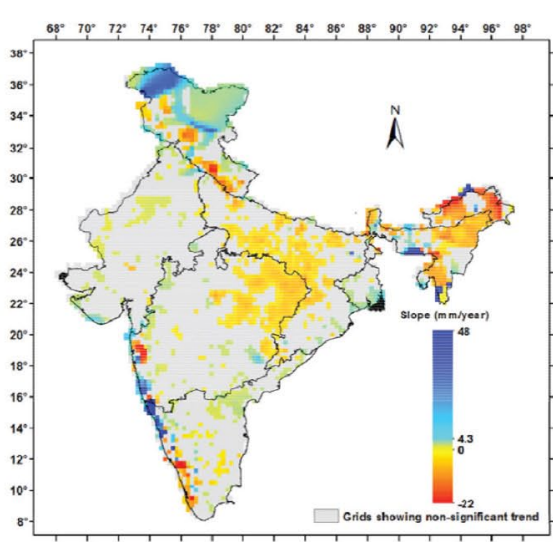

(a)

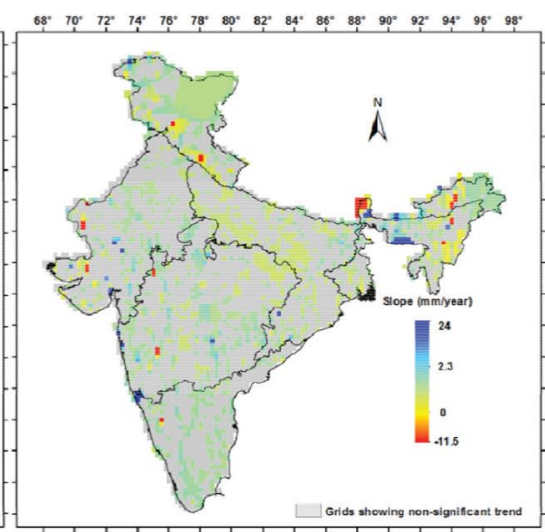

(b)

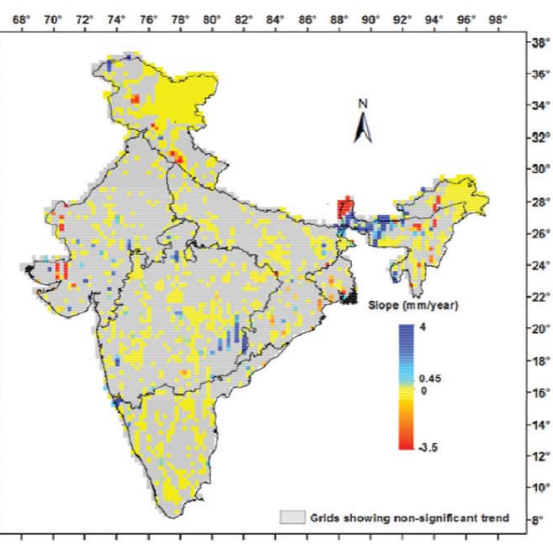

(c)

Figure 4: Spatial variation of trends of (a) P, (b) R95, and (c) R99 at a 95\% significance level from 1901-2015.

\section{Trend Analysis of R95}

A significant increasing trend was found for both the spatially averaged annual mean and SD of R95 with a trend magnitude of $0.42 \mathrm{~mm}$ year ${ }^{-1}$ and $1.11 \mathrm{~mm}_{\text {year }}{ }^{-1}$, respectively, for the period 1901-2015 (Figure $2 \mathrm{~b}$ ). A trend analysis at the grid level revealed that out of the total IMD grids, approximately $23.37 \%, 12.67 \%$ and $63.96 \%$ of the grids showed a significant increasing trend, a significant decreasing trend and a non-significant trend, respectively (Figure 3b). A non-uniform interannual variability for R95 was also found across India, illustrating a significant decreasing trend in some parts of Chhattisgarh, Uttar Pradesh, Bihar, Sikkim and Uttaranchal (Figure 4b). On the other hand, a significant increasing trend was found in Goa, Meghalaya and Jammu and Kashmir. Furthermore, approximately $8.7 \%$ of the IMD grids showed significant increasing trends in both P and R95 in some parts of the Western zone, Southern zone, Eastern zone, Central zone and Western Himalayan zone (including parts of the Indian states of Maharashtra, Goa, Karnataka, Andhra Pradesh, Meghalaya, Assam, Rajasthan and Jammu and Kashmir).

\section{Trend Analysis of R99}

Both the spatially averaged annual mean and SD of R99 showed a significant increasing trend with a magnitude of $0.31 \mathrm{~mm}^{\text {year }}{ }^{-1}$ and 
$0.74 \mathrm{~mm}_{\text {year }}$, , respectively, for the period 1901-2015 (Figure 2c). Out of the total IMD grids, approximately $28.4 \%$ and $2.2 \%$ of the cells showed significant inclining and declining trends, respectively, while the remaining grids showed non-significant trends (Figure 3c). A nonuniform trend was found for R99 throughout India. A significant decreasing trend for R99 was found in parts of Gujarat, Sikkim and Uttaranchal (Figure 4c). On the other hand, a significant increasing trend was found in Goa, Sikkim, Assam and West Bengal. As explained above for $\mathrm{P}$ and R95, approximately $8.2 \%$ of the IMD grids showed a significant increasing trend for P and R99 in parts of the Western zone, Southern zone, Eastern zone, Central zone and Western Himalayan zone. This was consistent with the states listed for P and R95. As for the overlapping areas for R95 and R99, reflecting a consistent increase in extreme precipitation, approximately $17.7 \%$ of the IMD grids showed increasing trends mostly in the Western zone, Southern zone, Eastern zone, Central zone and Western Himalayan zone (including portions of the states of Rajasthan, Maharashtra, Gujarat, Goa, Karnataka, Tamil Nadu, Andhra Pradesh, Telangana, some parts of Chhattisgarh, Madhya Pradesh and West Bengal, Assam, Meghalaya, Arunachal Pradesh and Jammu and Kashmir).

\section{Analysis of Temporal Shifts}

To determine whether significant shifts occurred in the time series of P, R95 and R99, we applied Pettitt's test for each IMD grid point.

\section{Change Point Analysis of $P$}

For P, 3.16\%, 15.89\%, $18.05 \%$ and $5.3 \%$ of the grid cells showed significant change points between 1921-1940, 1941-1960, 1961-1980 and 1981-2000, respectively (Figure 5a). The analysis indicated that most of the change points (almost 34\%) occurred between 1941-1980. The change points between 1941-1980 were found mostly in the Central zone, Northern zone, western part of the Southern zone, Eastern zone, North Eastern hilly zone and Western Himalayan zone (some parts of Chhattisgarh, Jharkhand, Madhya Pradesh, Bihar, Uttar Pradesh, Assam, Arunachal Pradesh, Meghalaya, Uttaranchal and Jammu and Kashmir) (Figure 6a). 

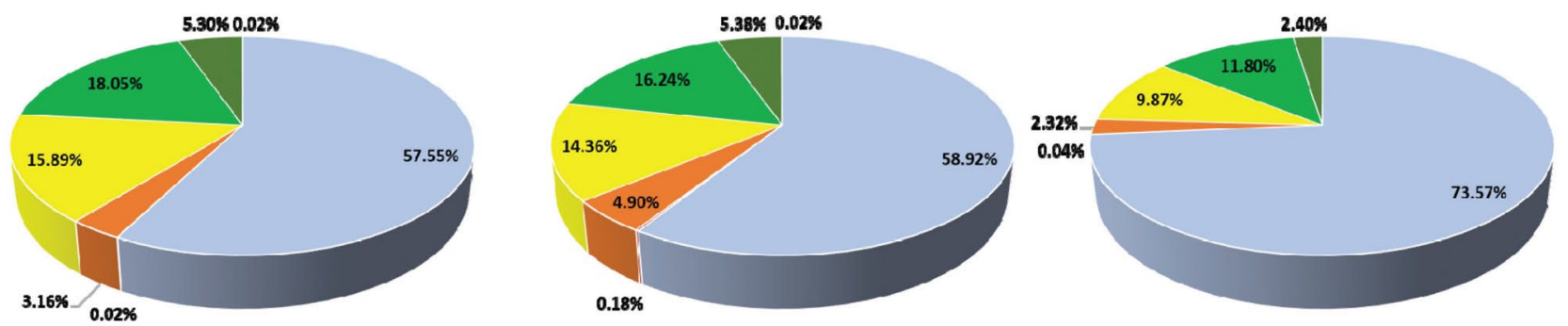

NS $\square 1901-1920 \square 1921-1940 \quad 1941-1960 \square 1961-1980 \square 1981-2000 \square 2001-2010$

(a)

(b)

(c)

Figure 5: Percentage of grid cells showing non-significant (NS) and significant ( $\mathrm{p}<$ o.05) change points in between 1901-1920, 1921-1940, 1941-1960, 1961-1980, 19812000 and 2001-2010 for (a) P, (b) R95 and (c) R99.

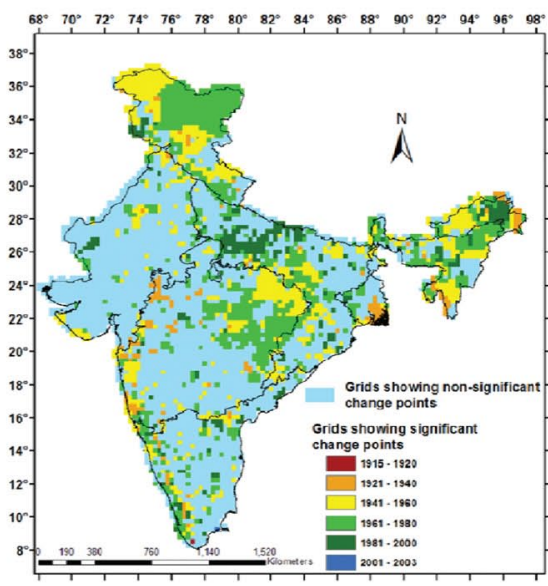

(a)

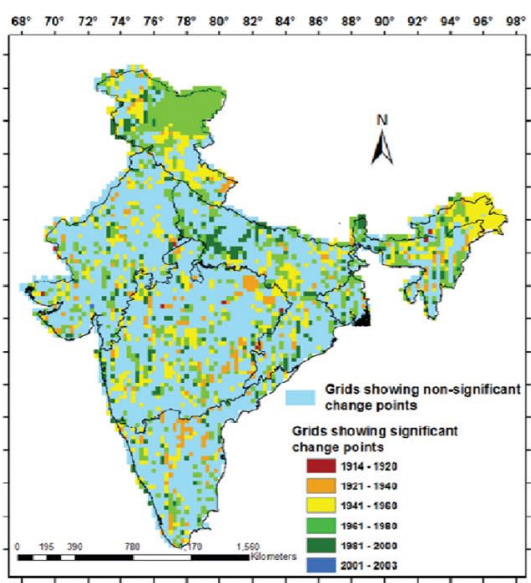

(b)

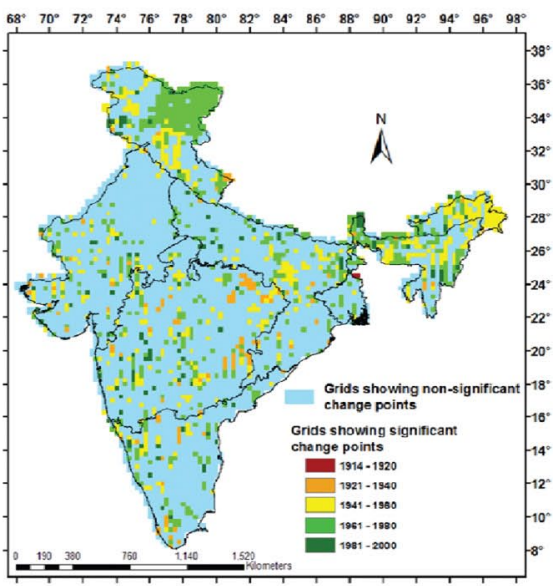

(c)

Figure 6: Spatiotemporal distribution of significant $(\mathrm{p}<0.05)$ and non-significant change pointsfor (a) P, (b) R95 and (c) R99 over India.

Change Point Analysis of R95

For extreme precipitation, R95, 4.9\%, 14.36\%, 16.24\% and 5.38\% of the grid cells were found to show significant change points between 1921-1940, 1941-1960, 1961-1980 and 1981-20oo, respectively (Figure 5b). Most of the change points (almost 31\%) were detected between 1941-1980. The change points between 1941-1980 were found mainly 


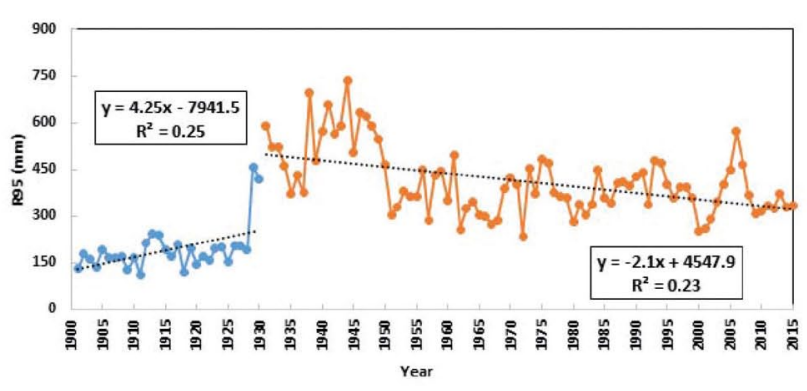

(a)

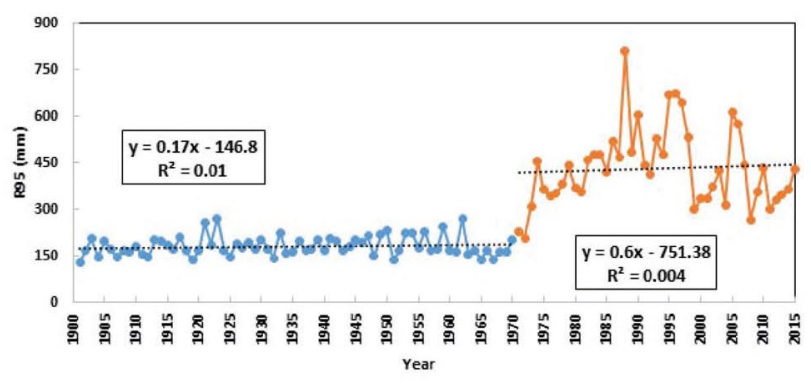

(c)

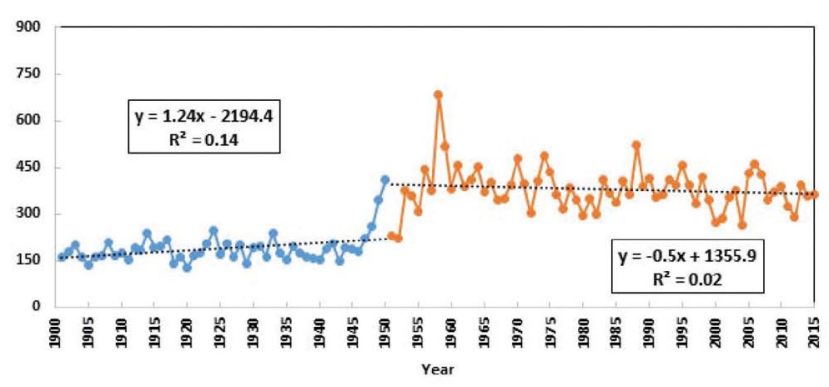

(b)

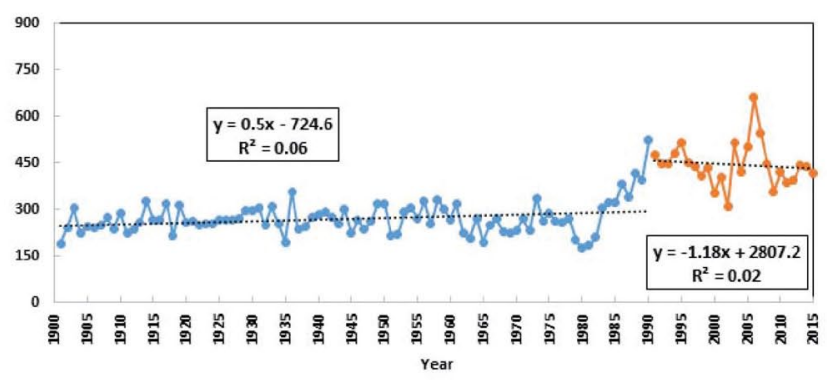

(d)

Figure 7: Temporal variation of heavy precipitation (R95) for grids showing significant change points as well as an increasing trend. For grids having significant change points between (a) 1921-1940, (b) 1941-196o, (c) 1961-1980 and (d) 19812000, the change points are 1930, 1950, 1970 and 1990, respectively.

in the lower part of the Central zone, western part of the Southern zone, upper part of the Northern zone, Western Himalayan zone, Eastern zone and North Eastern hilly zone (some parts of Maharashtra, Jharkhand, Assam, Arunachal Pradesh, Himachal Pradesh and Jammu and Kashmir) (Figure 6b). Grids showing significant change points between 1921-1940, 1941-1960, 1961-1980 and 1981-2000 were grouped to determine the linear trend of the time series before and after the shifting points for each of the groups.

Common change points considered for each time period on the grids falling under each of the groups were 1930 (1921-1940), 1950 (1940-1960), 1970 (1960-1980) and 1990 (1980-2000). Analyzing the grids showing an increasing trend and significant change points, we found that the trends before and after the shifting points were the opposite for R95 except for the grids showing change points between 1961-1980 (Figure 7). A temporal analysis of grids showing a decreasing trend of R95 and significant change points showed that the before 


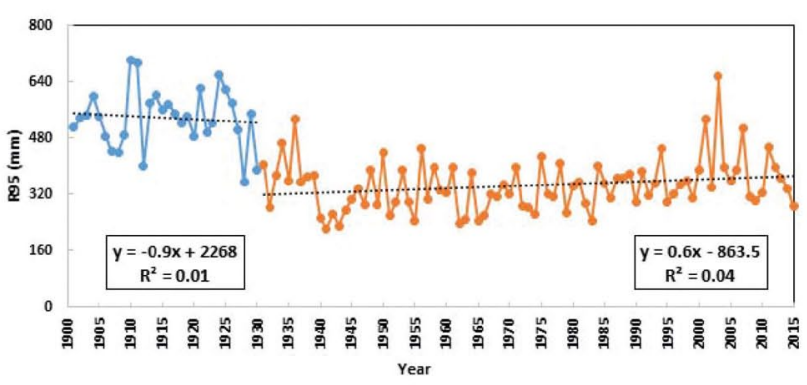

(a)

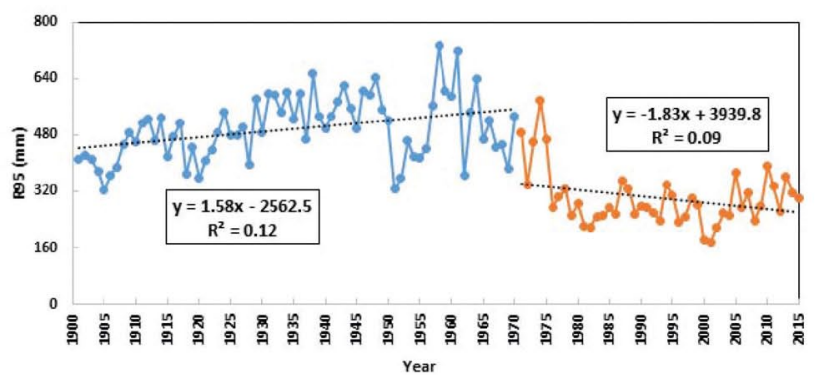

(c)

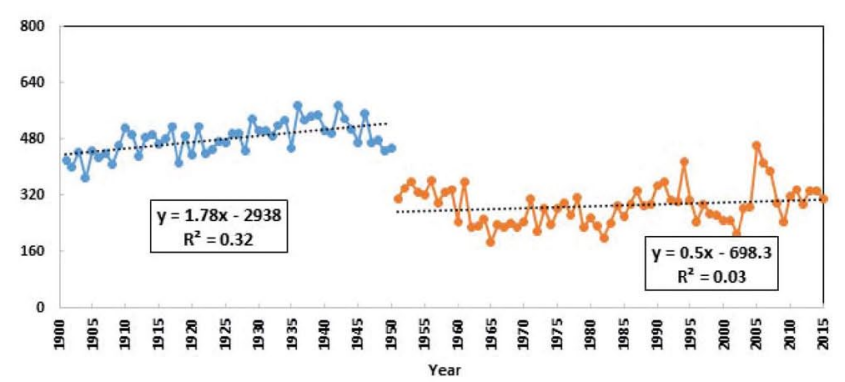

(b)

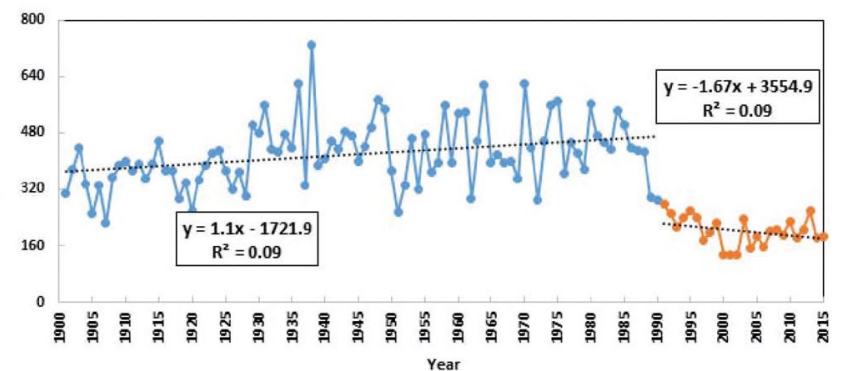

(d)

Figure 8: Temporal variation of heavy precipitation (R95) for grids showing significant change points as well as a decreasing trend. For grids having significant change points between (a) 1921-1940, (b) 1941-196o, (c) 1961-1980 and (d) 19812000, the change points are 1930, 1950, 1970 and 1990, respectively.

and after change point period showed opposite linear trends except for the grids having change points in between 1941-196o (Figure 8). The percentage of grids showing significant change points along with increasing/decreasing trends are shown in Table 1.

Table 1: Percentage of grid cells showing significant change points ( $95 \%$ significance level) with increasing/decreasing trend for R95 and R99 across India. These grids are used for temporal plots of R95 and R99

\begin{tabular}{lcccc} 
Time Span & $\begin{array}{c}\text { R95 } \\
\text { Increasing } \\
\text { Trend (\%) }\end{array}$ & $\begin{array}{c}\text { Decreasing } \\
\text { Trend (\%) }\end{array}$ & $\begin{array}{c}\text { Increasing } \\
\text { Trend (\%) }\end{array}$ & $\begin{array}{c}\text { Decreasing } \\
\text { Trend (\%) }\end{array}$ \\
\hline $1921-1940$ & 3.59 & 1.31 & 2.22 & 0.10 \\
$1941-1960$ & 8.40 & 5.96 & 8.88 & 0.99 \\
$1961-1980$ & 9.95 & 6.29 & 10.78 & 1.03 \\
$1981-2000$ & 2.94 & 2.44 & 2.24 & 0.16 \\
\hline
\end{tabular}




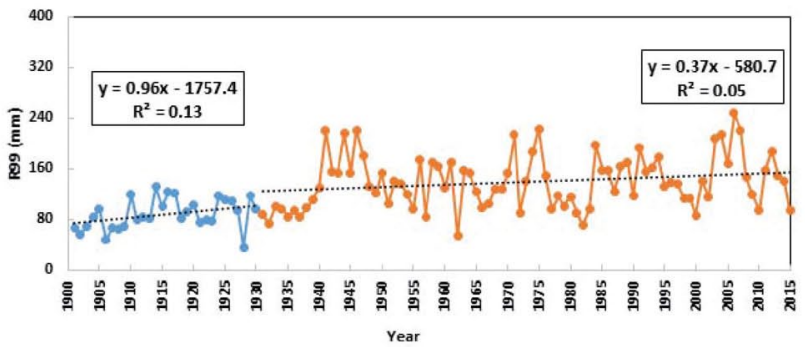

(a)

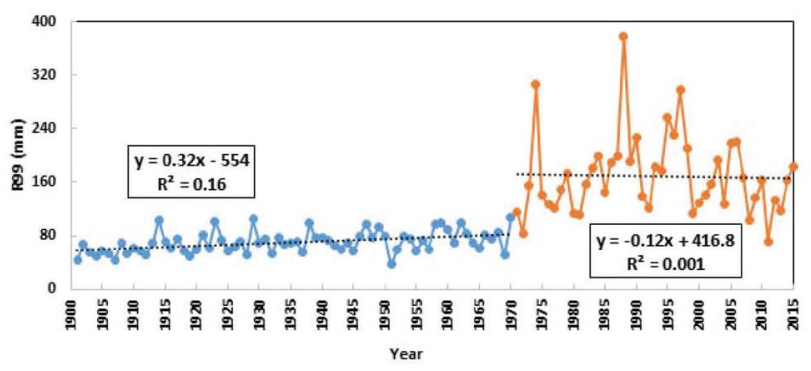

(c)

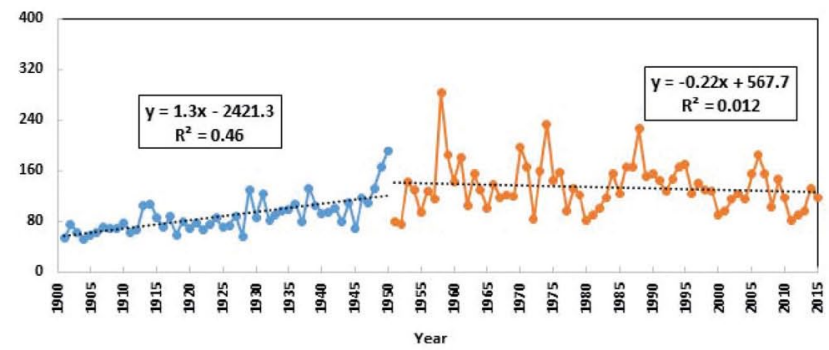

(b)

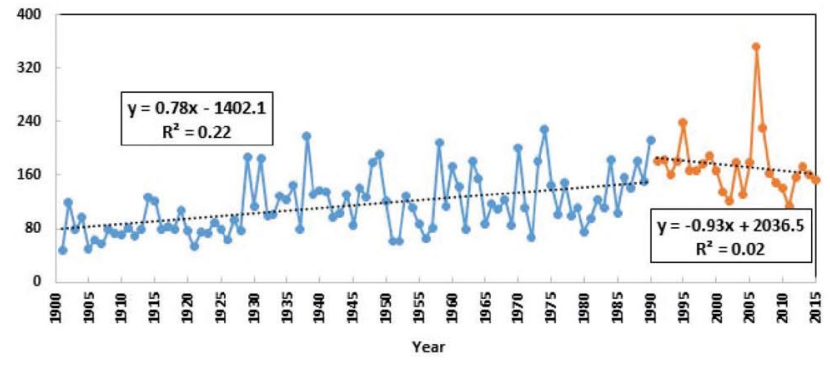

(d)

Figure 9: Temporal variation of extreme precipitation (R99) for grids showing significant change points as well as an increasing trend. For grids having significant change points between (a) 1921-1940, (b) 1941-196o, (c) 1961-1980 and (d) 19812000, the change points are 1930, 1950, 1970 and 1990, respectively.

\section{Change Point Analysis of R99}

In the case of the very extreme precipitation, R99, it was found that $2.32 \%, 9.87 \%, 11.8 \%$ and $2.4 \%$ of the grid cells showed significant change points between 1921-1940, 1941-1960, 1961-1980 and 19812000, respectively (Figure 5c). The analysis indicated that almost 22\% of the grid cells showed significant change points between the period 1941-1980. The change points between 1941-1980 were mostly found in the lower part of the Central zone, lower part of the Western zone, western part of the Southern zone, Western Himalayan zone, middle part of the Northern zone, North Eastern zone and North Eastern hilly zone (some parts of Jharkhand, Bihar, West Bengal, Assam, Arunachal Pradesh, Himachal Pradesh and Jammu and Kashmir) (Figure 6c). As was done with R95, grids having significant change points between 1921-1940, 1941-196o, 1961-1980 and 1981-2000 were grouped to determine any linear trend of the time series before and after change points for each of the groups for R99. Common change 


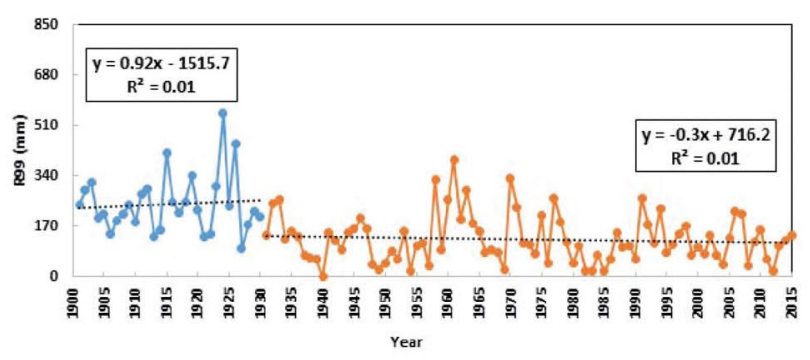

(a)

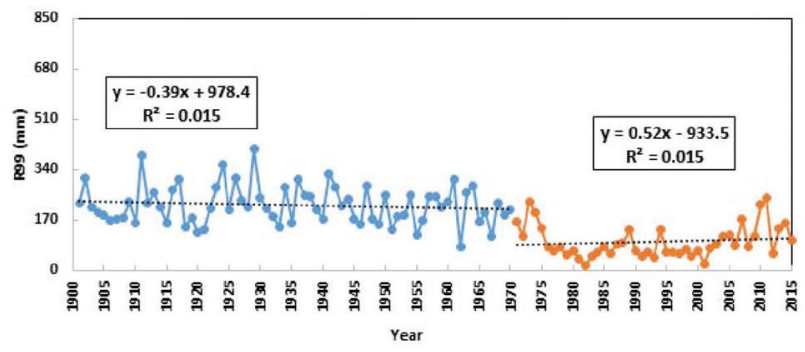

(c)

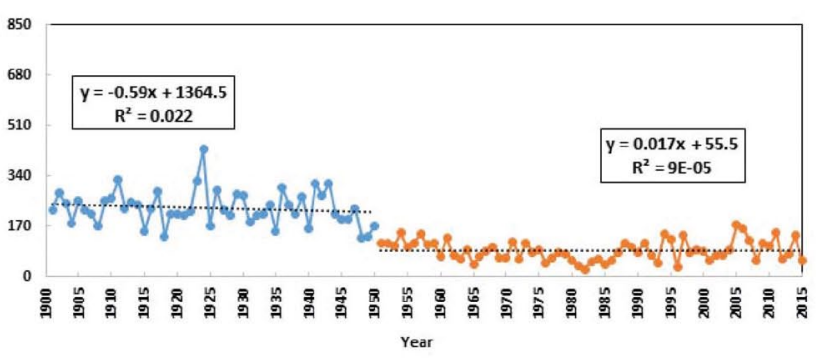

(b)

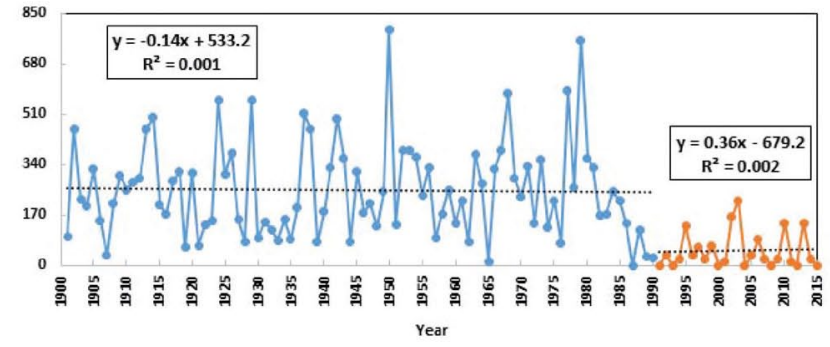

(d)

Figure 10: Temporal variation of extreme precipitation (R99) for grids showing significant change points as well as a decreasing trend. For grids having significant change points between (a) 1921-1940, (b) 1941-1960, (c) 1961-1980 and (d) 19812000, the change points are 1930, 1950, 1970 and 1990, respectively.

points considered for the grids falling under each of the groups which were 1930 (1921-1940), 1950 (1940-1960), 1970 (1960-1980) and 1990 (1980-2000). In the case of R99, an increasing trend was found for the pre-change point period whereas a decreasing trend was found for the post-change point period except for the grids showing significant change points between 1921-1940 (Figure 9). The same opposite trend was found for grids showing a decreasing trend of R99 and for significant change points (Figure 10).

\section{Discussion}

In this study, approximately $18.11 \%$ of India showed a significantly increasing trend in annual precipitation (P) whereas $20.29 \%$ of India showed a significantly decreasing trend in annual precipitation. Regarding extreme precipitation (R95), $23.37 \%$ of India showed a 
significantly increasing trend whereas $12.67 \%$ of India showed a significantly decreasing trend. Finally, for very extreme precipitation (R99), 28.4\% of India showed a significantly increasing trend whereas $2.2 \%$ of India showed a significantly decreasing trend. All of this suggests that as precipitation shifted toward extreme (R95) to very extreme (R99), more grid cells showed significant increasing trends. Hence, these trends indicate that some regions are more physically vulnerable. Grids showing increasing trends in both P and R95 (8.7\% of the Indian territory) and both P and R99 (8.2\% of the Indian territory) could be termed regions more vulnerable to climate extremes.

As an increase in the frequency and magnitude of extreme precipitation may render urban and agricultural infrastructure more vulnerable, such regions will need efficient planning, management and adaptation policies to cope with climate extremes. Goswami et al. (2006) also showed no significant trend in a spatially averaged time series of seasonal monsoon rainfall from $1951-2000$ using $1^{\circ} \times 1^{\circ}$ gridded rainfall data. In contrast, a significant increasing trend for monsoon extreme precipitation was found in previous studies (Rajeevan et al., 2008; Vittal et al., 2013). The present study contributed to identifying significant increases in extreme precipitation that occurred annually including the monsoon period (June-September). Furthermore, the non-uniform distribution of spatial trends with increasing variability of extreme rainfall corroborated previous findings (Ghosh et al., 2009; Krishnamurthy et al., 2009; Ghosh et al., 2012; Mondal and Mujumdar, 2015).

Various scientists have tried to determine what may be causing these precipitation changes. Rajeevan et al. (2008) pointed out that the higher sea surface temperature and latent heat flux over the tropical Indian Ocean contributed to the interdecadal variability of rainfall extreme events in India. Roxy et al. (2017) pointed out that the increase in variability of the low-level monsoon westerlies over the Arabian Sea was one of the key factors in the increase in extreme rainfall events over central India. Increasing trend in extreme precipitation in the Western Ghats was mainly attributed to the presence of convective clouds in a moist adiabatic stratification environment (Maheshkumar et al., 2014). Moreover, offshore troughs and vortices also play a major role in extreme precipitation in this region (Francis and Gadgil, 2006). Yang et al. (2018) showed the influence of atmospheric 
rivers (which transport water vapour through long narrow corridors from the regions of tropics to the regions of high latitudes of Himalayas) to be responsible for extreme precipitation during winter in the northern and north-eastern India. Western Disturbances were also found to be responsible for extreme winter precipitation in northern India, which further enhances its effect on the foothills of Himalaya due to the orographic effect (Dimri et al., 2015). Whereas the studies of Hurley and Boos, (2015) and Yang et al. (2018) pointed out tropical lows or tropical depressions causing the summer time extreme precipitation in northern India.

These climate attributions redistribute precipitation in time and space, creating conspicuous and significant shifts in the interannual regimes of P, R95 and R99. Thus, the change point analyses and associated trends during before and after change point periods may help improve planning and designing infrastructure across scales and in different regions of India. Mapped shifting points evidenced a spatial distribution of changes in precipitation regimes (Figures 5 and 6) and corresponding areas (characterized by the aggregated grid cells), identifying their occurrence as decreasing or increasing trends. The identification of areas of significant shifts in the P, R95 and R99 trends affects regional planning, redesign and management of infrastructure. The identification of those areas may allow policy makers and regional planners to identify where to invest in and update civil infrastructure and manage water and energy resources adaptively. For example, similar areas with significant shifting points for P and R95 between 1910 and 2010 (and between 1941 and 1980) encompassed approximately $42.44 \%(33.94 \%)$ and $41.08 \%(30.6 \%)$ of India's territory in contrast with the $26.43 \%(21.67 \%)$ of India where very extreme precipitation occurs. At the same time, of those areas that showed significant shifts between 1941 and 1980, 25\% and 16\% of the grid cells showed increasing and decreasing trends in extreme precipitation (R95), respectively, and $24 \%$ and $2 \%$ of the areas of significant shifts showed increasing and decreasing trends in very extreme precipitation (R99) (Table 1). In this context, adaptive management of water resources might be focused on flood control instead of long-term water storage, as suggested by the shifts of extreme to very extreme precipitation, and the predominance of areas with significant increasing trends (between 1941-1980). 
If we consider the suggested distribution of shifting points, in opposition to the single shifting point previously suggested as occurring in 1975 (Vittal et al., 2013) and between 1971-1981 (Crook and Dyson, 1982; Mohan and Pant, 1982), which is consistent with the findings of this study, investments and planning can be costly due to this generalization. The present study found significant change points before 1970, which suggests that temporal shifts in precipitation extremes do not always depend on factors such as urbanization. The same conclusion was also drawn by Kishtawal et al. (2010) and Vittal et al. (2013). Sahana et al. (2015) attributed a record of varying monsoon parameters post-1976/77 to regime shift experienced by the tropical Pacific sea surface temperatures leading to significant changes in moisture flux, specific humidity and wind velocity. Further, Ghosh et al. (2009) also observed changes in trends after $1976 / 77$, which the authors attributed to urbanization, deforestation and industrialization. Finally, Vittal et al. (2013) also found opposing trends leading up to and leading away from a change point of 1950, replicating the same pattern found in this study.

\section{Conclusion}

In this study, spatiotemporal trends and temporal shifts were analyzed for long-term precipitation and extreme precipitation indices over mainland India. From the results and discussions, the following conclusions may be drawn:

1. No significant trend was found for normal annual precipitation, but there was a significant non-uniform increasing trend found for the spatially averaged mean and standard deviation of R95 and R99. Trend analysis of normal annual precipitation at the IMD grid level showed an increasing trend in northern and northeastern India and its western coast but decreasing trends over central India and several regions of northeastern India. On the other hand, a significant increasing trend was found for R95 and R99 events in some parts of northeastern India and its west coast. In this trend, sea surface temperature, latent heat flux over the tropical Indian Ocean and an increase in variability of the low-level monsoon westerlies over the Arabian Sea might have played a key role. As precipitation 
shifted toward extreme (R95) to very extreme (R99), more grid cells showed significant increasing trends and, hence, transformed into more vulnerable regions. Increases in extreme rainfall events may lead to events like flash floods, requiring better planning and management of infrastructure to cope with them.

2. Change point analysis shows that temporal shifts in the time series of annual precipitation (P), extreme precipitation (R95) and very extreme precipitation (R99) occurred primarily between 19411980 for almost $31 \%$ and then almost $22 \%$ of the grids mostly in the Western Himalayan zone, Northern zone, Central zone, North Eastern zone and North Eastern hilly zone of India. Further, change points between 1981-2000 were found in the states of Uttar Pradesh, Rajasthan, Jammu and Kashmir and Sikkim. The spatiotemporal variation of change points suggests that the effects of urbanization as well as climatic factors might have played a key role in this regard. This also suggests that different change points for different grids should be considered rather than considering a common change point for all grids while analyzing spatiotemporal heterogeneity and the return period of heavy precipitation events. This technique enables better evaluation of any infrastructure's life expectancy.

3. The trend of extreme precipitation found during the pre-change point period was opposite that of the post-change point period for grids showing significant temporal shifts in extreme and very extreme precipitation. This suggests that incorporating change point analysis could help in understanding the change in distribution and trends in extreme precipitation regionally.

The methodology used and the results found in this study will be useful for future work in understanding the spatiotemporal trends of climate extremes and their temporal shifts over time.

Acknowledgments - The authors acknowledge the support provided by the University of Nebraska-Lincoln's Quantitative Life Sciences Initiative and the Department of Biological Systems Engineering. Some research ideas and components were also developed within the framework of the USDA National Institute of Food and Agriculture, Hatch project NEB-21-166 Accession No.1009760. The authors appreciate the valuable comments of the reviewers. 


\section{References}

Alexander, L.V., Zhang, X., Peterson, T.C., Caesar, J., Gleason, B., Klein Tank, A.M.G., Haylock, M., Collins, D., Trewin, B., Rahimzadeh, F. and Tagipour, A., 2006. Global observed changes in daily climate extremes of temperature and precipitation. Journal of Geophysical Research: Atmospheres, 111(D5).

Ali, H., Mishra, V. and Pai, D.S., 2014. Observed and projected urban extreme rainfall events in India. Journal of Geophysical Research: Atmospheres, 119(22): 12,621-12,641.

Allen, M. R. and Ingram, W.J., 2002. Constraints on future changes in climate and the hydrologic cycle. Nature, 419(6903): 224-232.

Crook, N. and Dyson, T., 1982. Urbanization in India: Results of the 1981 census. Population and Development Review, 145-155.

Dash, S.K., Kulkarni, M., Mohanty, U.C. and Prasad, K., 2009. Changes in the characteristics of rain events in India. Journal of Geophysical Research: Atmospheres, 114(D10). doi:10. 1029/2008SD010572

De, U.S., Dube, R.K. and Prakasa Rao, G.S., 2005. Extreme weather events over India in the last 100 years. The Journal of Indian Geophysical Union, 9(3): 173-187.

Dimri, A.P., Niyogi, D., Barros, A.P., Ridley, J., Mohanty, U.C., Yasunari, T. and Sikka, D.R., 2015. Western disturbances: A review. Reviews of Geophysics, 53(2): 225-246.

Disaster Relief Emergency Fund, 2016. DREF final report India: Floods. https:// reliefweb.int/sites/reliefweb.int/files/resources/MDRINo16fr-DREF.pdf.

Francis, P.A. and Gadgil, S., 2006. Intense rainfall events over the west coast of India. Meteorology and Atmospheric Physics, 94(1-4): 27-42.

Ghosh, S., Luniya, V. and Gupta, A., 2009. Trend analysis of Indian summer monsoon rainfall at different spatial scales. Atmospheric Science Letters, 10(4): 285-290.

Ghosh, S., Das, D., Kao, S.C. and Ganguly, A.R., 2012. Lack of uniform trends but increasing spatial variability in observed Indian rainfall extremes. Nature Climate Change, 2(2): 86-91.

Goswami, B.N., Venugopal, V., Sengupta, D., Madhusoodanan, M.S. and Xavier, P.K., 2006. Increasing trend of extreme rain events over India in a warming environment. Science, 314(5804): 1442-1445.

Hirsch, R.M., Slack, J.R. and Smith, R.A., 1982. Techniques of trend analysis for monthly water quality data. Water Resources Research, 18(1): 107-121.

Hurley, J.V. and Boos, W.R., 2015. A global climatology of monsoon low-pressure systems. Quarterly Journal of the Royal Meteorological Society, 141(689): 1049-1064.

Kendall, M.G., 1955. Rank Correlation Methods. London: Griffin.

Kishtawal, C.M., Niyogi, D., Tewari, M., Pielke Sr., R.A. and Shepherd, J.M., 2010. Urbanization signature in the observed heavy rainfall climatology over India. International Journal of Climatology, 30(13): 1908-1916. 
Kotal, S.D., Roy, S.S. and Roy Bhowmik, S.K., 2014. Catastrophic heavy rainfall episode over Uttarakhand during 16-18 June 2013: Observational aspects. Current Science, 107(2): 234-245.

Krishnamurthy, C.K.B., Lall, U. and Kwon, H.H., 2009. Changing frequency and intensity of rainfall extremes over India from 1951 to 2003. Journal of Climate, 22(18): 4737-4746.

Maheskumar, R.S., Narkhedkar, S.G., Morwal, S.B., Padmakumari, B., Kothawale, D.R., Joshi, R.R. ... Kulkarni, J.R., 2014. Mechanism of high rainfall over the Indian west coast region during the monsoon season. Climate Dynamics, 43(5-6): 1513-1529.

Mann, H. B., 1945. Nonparametric tests against trend. Econometrica: Journal of the Econometric Society, 13(3): 245-259.

Meher, J.K., Das, L., Benestad, R.E. and Mezghani, A., 2018. Analysis of winter rainfall change statistics over the Western Himalaya: The influence of internal variability and topography. International Journal of Climatology, 38(S1): e475-e496.

Min, S.K., Zhang, X., Zwiers, F.W. and Hegerl, G.C., 2011. Human contribution to more-intense precipitation extremes. Nature, 470(7334): 378-381.

Mohan, R. and Pant, C., 1982. Morphology of urbanisation in India: Some results from 1981 census. Economic and Political Weekly, 17(39): 1579-1588.

Mondal, A. and Mujumdar, P.P., 2015. Modeling non-stationarity in intensity, duration and frequency of extreme rainfall over India. Journal of Hydrology, 521: 217-231.

Pai, D.S., Sridhar, L., Rajeevan, M., Sreejith, O.P., Satbhai, N.S. and Mukhopadhyay, B., 2014. Development of a new high spatial resolution $\left(0.25^{\circ} \times 0.25^{\circ}\right)$ long period (1901-2010) daily gridded rainfall data set over India and its comparison with existing data sets over the region. Mausam, 65(1): 1-18.

Pettitt, A.N., 1979. A non-parametric approach to the change-point problem. Applied Statistics, 28(2): 126-135.

Rajeevan, M., Bhate, J. and Jaswal, A.K., 2008. Analysis of variability and trends of extreme rainfall events over India using 104 years of gridded daily rainfall data. Geophysical Research Letters, 35(18). doi: 10.1029/2008GL035143

Roxy, M.K., Ghosh, S., Pathak, A., Athulya, R., Mujumdar, M., Murtugudde, R., Terray, P. and Rajeevan, M., 2017. A threefold rise in widespread extreme rain events over central India. Nature Communications, 8(1): 708.

Sahana, A.S., Ghosh, S., Ganguly, A. and Murtugudde, R., 2015. Shift in Indian summer monsoon onset during 1976/1977. Environmental Research Letters, 10(5): 054006.

Sen, P.K., 1968. Estimates of the regression coefficient based on Kendall's tau. Journal of the American Statistical Association, 63(324): 1379-1389.

Singh, N. and Ranade, A.A., 2009. Climatic and hydroclimatic features of wet and dry spells and their extremes across India (IITM Research Report No. 122). Pune, India: Indian Institute of Tropical Meteorology.

Stocker, T.F., Qin, D., Plattner, G.K., Tignor, M., Allen, S.K., Boschung, J., Nauels, A., Xia, Y., Bex, V. and Midgley, P.M., 2013. IPCC, 2013: Climate Change 2013: The Physical Science Basis. Contribution of Working Group I to the Fifth Assessment Report of the Intergovernmental Panel on Climate Change, 1535 pp. 
Sushama, L., Ben Said, S., Khaliq, M.N., Nagesh Kumar, D. and Laprise, R., 2014. Dry spell characteristics over India based on IMD and APHRODITE datasets. Climate Dynamics, 43(12): 3419-3437.

Trenberth, K.E. (2011). Changes in precipitation with climate change. Climate Research, 47(1-2): 123-138.

Vinnarasi, R. and Dhanya, C.T., 2016. Changing characteristics of extreme wet and dry spells of Indian monsoon rainfall. Journal of Geophysical Research: Atmospheres, 121(5): 2146-216o.

Vittal, H., Karmakar, S. and Ghosh, S., 2013. Diametric changes in trends and patterns of extreme rainfall over India from pre-1950 to post-1950. Geophysical Research Letters, 40(12): 3253-3258.

Westra, S., Alexander, L.V. and Zwiers, F.W., 2013. Global increasing trends in annual maximum daily precipitation. Journal of Climate, 26(11): 3904-3918.

Wu, P., Christidis, N. and Stott, P.A. (2013). Anthropogenic impact on Earth's hydrological cycle. Nature Climate Change, 3(9): 807-810.

Yang, Y., Zhao, T., Ni, G. and Sun, T. (2018). Atmospheric rivers over the Bay of Bengal lead to northern Indian extreme rainfall. International Journal of Climatology, 38(2): 1010-1021. 